\title{
Do weaponless males of the hermit crab Pagurus minutus give up contests without escalation? Behavior of intruders that lack their major cheliped in male-male contests
}

\author{
Chiaki I. Yasuda ${ }^{1}$ Tsunenori Koga'
}

Received: 3 March 2016/Accepted: 24 April 2016/Published online: 4 May 2016

(C) Japan Ethological Society and Springer Japan 2016

\begin{abstract}
In dyadic contests, theoretical studies have predicted that weaker contestants are less likely to engage in fights to minimize the cost of aggression. Since the major cheliped of decapod crustaceans is critically important as a weapon, contestants without a major cheliped should be more likely to give up the contests. We therefore examined whether loss of the major cheliped by the hermit crab Pagurus minutus would affect their decision to escalate male-male contests over guarded females. Intruders without a major cheliped showed no difference in the frequency of escalation compared with intact intruders, and the decision to give up was affected by the body size difference between the contestants. After escalation, compared with intact intruders, intruders without a major cheliped had significantly decreased success of takeover of a female from opponents, suggesting a strong disadvantage of losing their major cheliped. Although the decision of weaponless intruders to escalate seems irrational, several factors, such as poor accuracy of resource holding potential assessment, the influence of body size, and a high benefit to cost ratio of male-male contests, may have affected their behavior.
\end{abstract}

Keywords Assessment · Autotomy · Decision making · Male-male competition $\cdot$ Resource holding potential

Chiaki I. Yasuda

chiaki.y.0210@gmail.com

1 Faculty of Education, Wakayama University, Sakaedani 930, Wakayama 640-8510, Japan

\section{Introduction}

Dyadic contests for limited resources are common in animals (Huntingford and Turner 1987; Hardy and Briffa 2013). In these contests, asymmetrical fighting ability and/ or resource holding potential (RHP; Parker 1974) are among the most important factors that determine outcomes. Since RHP is often determined by body or weapon size, contestants with a larger body or weapon size show a higher, whereas smaller or weaponless contestants show a lower, probability of winning (Maginnis 2006; Fleming et al. 2007; Arnott and Elwood 2009). Such weaker contestants often pay a greater cost associated with aggression (Parker 1974) than stronger contestants (Searcy and Nowicki 2005), especially when contests escalate to more intense or costly phases. For example, Neat et al. (1998) suggests that, in the cichlid fish Tilapia zilli, male contestants incur injury and energy costs during escalated fights. Although the contest escalation is costly for both stronger and weaker individuals, weaker contestants face a more severe condition. Potentially weaker contestants therefore avoid contests by avoiding escalation or adopting a lower level of aggression (e.g., Okada and Miyatake 2010; Yasuda et al. 2012; Li et al. 2014).

Decapod crustaceans are one of the most studied taxa in terms of the functions of their morphological weapons in contest competition (Searcy and Nowicki 2005). Most of these animals possess an enlarged (i.e., major) cheliped, and this is a critically important predictor of the winner in dyadic contests (Emlen 2008; Briffa 2013). Contestants often use their major cheliped as both a visual advertisement of their fighting ability and a substantial weapon (e.g., Crane 1975; Hughes 1996; Sneddon et al. 1997; Moore 2007), and, in some species, having a larger major cheliped improves fighting success more than having a large body 
(Barki et al. 1997; Sneddon et al. 1997; Yoshino et al. 2011). If a contestant has lost its major cheliped, it has a lower probability of winning contests than an intact contestant (Smith 1992; Juanes and Smith 1995; Daleo et al. 2009), especially when the weaponless contestant initiates a contest with a resource-holding opponent (Abello et al. 1994). Intruders without a major cheliped also engage in fewer contests in the hermit crab Pagurus bernhardus (Neil 1985) and the fiddler crab Uca annulipes (Booksmythe et al. 2010). Such intruders might therefore avoid fruitless contests and minimize their potential fighting costs by abandoning contests at an early stage, instead of escalating.

Males of Pagurus hermit crabs use an enlarged right (i.e., major) cheliped as a weapon in contests for females during the reproductive season (Yasuda et al. 2011, 2012, 2014). Males grasp the aperture of the gastropod shell occupied by a sexually mature female for several days (Imafuku 1986; Elwood and Neil 1992; Goshima et al. 1998), and male-male contests over the female often occur between a solitary intruder and a guarding male. In contests between intact males, the outcomes are determined by major cheliped size rather than body size in P. middendorffii (Yasuda et al. 2012) and P. minutus (Yasuda and Koga in submission). Males without a major cheliped, therefore, are expected to be less willing to escalate in male-male contests. However, Yasuda et al. (2011) have reported that in P. nigrofascia, intruders without a major cheliped actively escalate the fight against intact guarding males even though the loss of the major cheliped clearly decreases the probability of winning in male contestants. Since $P$. nigrofascia intruders typically escalate the contest whenever they encounter a guarding opponent (e.g., $100 \%$ of the time; Suzuki et al. 2012; Yasuda et al. 2015), this species might not be a suitable choice to examine the factors affecting an intruder's decision about whether to give up or escalate a contest. Further study using other Pagurus species will be needed to clarify the relationship between an individual without a major cheliped and the decision to give up.

In the present study, we examined whether loss of the major cheliped by males of $P$. minutus affected an intruder's decision to give up at an early stage (i.e., before escalation) in male-male contests. In this species, some intact intruders give up contests before escalation if their major cheliped is smaller than those of their opponents (Yasuda and Koga, in submission). The decision of a $P$. minutus intruder would therefore be affected by the status of their own major cheliped, and intruders without a major cheliped might show different contest behavior from intact intruders. When the contests were escalated by intruders, we also compared the success of takeover in intact intruders and intruders without a major cheliped to examine the magnitude of the disadvantage caused by loss of the major cheliped in this species.

\section{Materials and methods}

We collected 174 precopulatory guarding pairs of $P$. minutus from a sandy mud flat at Nunohiki, in the Waka River estuary, Wakayama, Japan $\left(34^{\circ} 10^{\prime} 23^{\prime \prime} \mathrm{N}, 135^{\circ} 10^{\prime} 49^{\prime \prime} \mathrm{E}\right)$, from 19 December 2014 to 9 January 2015; the mating season of this species at this site occurs from November to April (Koga unpublished data). In the laboratory, if a male was still guarding the female, we placed the pair in a container $(8 \times 12.5 \times 8 \mathrm{~cm})$ containing natural seawater to a depth of $2.5 \mathrm{~cm}$. All the pairs were acclimated to laboratory conditions for at least an hour before the experimental tests of male-male contest, and all tests were conducted within $6 \mathrm{~h}$ of collection.

For each contest, we placed one male (the owner) and his partner in an arena $(11 \times 19.5 \times 8.5 \mathrm{~cm})$. To prevent any appendages from protruding from the water surface during the interaction, the arena contained seawater to a depth of $3 \mathrm{~cm}$. After confirming guarding by the owner, we introduced another male (the intruder) randomly chosen from the other pairs into the arena after separating him from his partner. All owners (guarding males) had a major cheliped; that is, they were intact. Using a digital camera (WG-10, Pentax), we recorded the interactions between the males from the time the intruder was introduced into the arena. A total of 71 recordings of the contests were observed for up to $15 \mathrm{~min}$ from the time when the intruder initiated movement. When the intruder initiated grappling with the owner (for details of this behavior, see Yasuda et al. 2012), we considered that the contest had escalated. In the escalated contests, we recorded whether the intruder succeeded in taking the female from its original owner.

After the contests, we measured the shield length (SL, calcified anterior portion of the cephalothorax) of all crabs as an index of their body size. Measurement was to the nearest $0.01 \mathrm{~mm}$ and was performed under a stereomicroscope. We also recorded whether the intruder had a major cheliped (intruders without a major cheliped; $N=15$, intact intruders; $N=56$ ). Mean SL in weaponless intruders $(3.91 \pm 0.19 \mathrm{SD} \mathrm{mm})$ was significantly larger than that in intact intruders $(3.76 \pm 0.37 \mathrm{SD} \mathrm{mm} ; t$-test, $t=2.16$, $P=0.035$ ). Except for data on contests involving a male without a major cheliped, the data in this study were also used in Yasuda and Koga (in submission), in which we examined the assessment strategy of intruders during male-male contests. Previous studies have reported that the lack of chelipeds in crustaceans is due to escape from a predator (e.g., Juanes and Smith 1995), and the hermit crab $P$. middendorffii autotomize its major cheliped in anti- 
predatory behavior against a predatory crab (Matsuo et al. $2015 b$ ). Since there is a significant highly positive correlation between shield length and major cheliped length in males of $P$. minutus (Yasuda and Koga in submission), weaponless intruders may also have possessed a large major cheliped prior to its loss and might have autotomized the cheliped to escape from attracted predators. On the other hand, since few Pagurus males are injured in intraspecific aggression (e.g., Yasuda et al. 2011), weaponless or not is expected to be independent of the relative strength to conspecifics. A fouled molting event is another explanation of the lack of cheliped (Maginnis 2006). Although no data exist, these possibilities might explain why weaponless males in P. minutus had autotomized their major cheliped before collection in this study. All statistical analyses were performed using version 3.2.2 of the R software ( $\mathrm{R}$ Core Team 2015).

We used a generalized linear model (GLM) with a binomial error distribution to examine whether weaponless intruders gave up the contest without grappling. The response variable was a binary variable that defined whether the intruder gave up the contest without grappling (yes $=1$, no $=0 ; N=71$ ). The explanatory variables were whether the intruder had lost its major cheliped (loss $=1$, intact $=0$ ) and the difference in SL between the intruder and the owner. The SL of females guarded by the owners was also treated as an explanatory variable in the GLM. We then examined the effect of lacking a major cheliped on the success of takeover in intruders after escalation $(N=61)$. Another response variable was whether intruders succeeded in takeover (yes $=1$, no $=0$ ). The explanatory variables were the same as in the analysis of whether males gave up the contests.

\section{Results}

Table 1 summarizes the results of the male-male contests. Regardless of the presence or absence of a major cheliped, few intruders gave up the contest without escalation $(N=10,14.1 \%)$, so most intruders initiated grappling $(N=61,85.9 \%)$. There was no significant difference in the probability of giving up between intruders without a major cheliped and intact intruders (Table 2; Fig. 1). Intruders with a smaller SL than the opponents' were significantly less likely to grapple with the owner (Table 2; Fig. 1). In the escalated contests, intruders that lacked their major cheliped had a significantly lower frequency of success of takeover than intact intruders (Table 2; Fig. 2). Intruders with a large SL relative to that of their opponents had a significantly higher chance of success of takeover (Table 2). In intruders that lacked their major cheliped, all three of the males that succeeded in takeover had a larger SL than their opponents (Fig. 2). The SL of the female had no significant effect on either escalation of the contest or the intruder's success in takeover (Table 2).
Table 1 Summary of malemale contests of Pagurus minutus

Table 2 Results of male-male contests in Pagurus minutus

\begin{tabular}{|c|c|c|c|c|c|c|c|c|c|}
\hline \multirow[t]{3}{*}{ Status of intruders } & \multirow[t]{3}{*}{$N$} & \multicolumn{4}{|c|}{ Before escalation } & \multicolumn{4}{|c|}{ After escalation } \\
\hline & & \multicolumn{2}{|c|}{ Giving up } & \multicolumn{2}{|c|}{ Escalation } & \multicolumn{2}{|c|}{ Success in takeover } & \multicolumn{2}{|c|}{ Failure in takeover } \\
\hline & & $N$ & $(\%)$ & $N$ & $(\%)$ & $N$ & $(\%)$ & $N$ & $(\%)$ \\
\hline Loss of major cheliped & 15 & 1 & (6.7) & 14 & (93.3) & 3 & (21.4) & 11 & (78.6) \\
\hline Intact & 56 & 9 & $(16.1)$ & 47 & (83.9) & 29 & $(61.7)$ & 18 & $(38.3)$ \\
\hline
\end{tabular}

\begin{tabular}{|c|c|c|c|c|}
\hline & Estimate & SE & $z$ & $P$ \\
\hline \multicolumn{5}{|c|}{ Whether intruders gave up the contest $(N=71)$} \\
\hline Intercept & -0.06 & 2.59 & -0.02 & 0.98 \\
\hline Loss of major cheliped & 0.62 & 1.19 & 0.52 & 0.61 \\
\hline Difference in shield length & 3.18 & 1.03 & 3.10 & $<0.01$ \\
\hline Shield length of female & 0.87 & 0.96 & 0.91 & 0.37 \\
\hline \multicolumn{5}{|c|}{ Whether intruders succeeded in takeover of the female from the owners $(N=61)$} \\
\hline Intercept & -0.65 & 2.38 & -0.27 & 0.78 \\
\hline Loss of major cheliped & -2.76 & 0.90 & -3.07 & $<0.01$ \\
\hline Difference in shield length & 3.86 & 1.24 & 3.11 & $<0.01$ \\
\hline Shield length of female & 0.41 & 0.86 & 0.46 & 0.64 \\
\hline
\end{tabular}

Analysis was based on a GLM with a binomial error distribution 


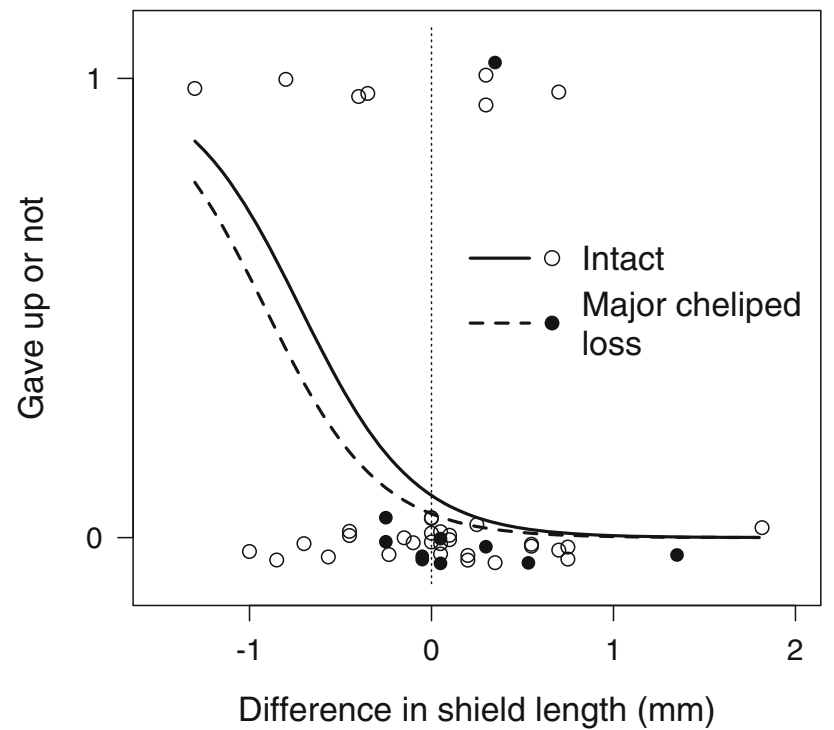

Fig. 1 Logistic regression results for whether intruders gave up the contest without escalation (i.e., without grappling) in male-male contests of Pagurus minutus. The curves were estimated using a GLM with a binomial error distribution. Values of 0 and 1 represent intruders that escalated or gave up the contest, respectively. Shield length of the females guarded by owners was treated as the average value in the curves. The vertical dotted line indicates no body size difference between the males. Note that there was no significant difference in frequency of escalation between intact intruders and intruders without a major cheliped (Table 2)

\section{Discussion}

The lack of a major cheliped had no effect on the decision of intruders to escalate during male-male contests in $P$. minutus. Intruders of this species showed a lower frequency of escalation when they were smaller than their opponent (based on SL), but loss of their major cheliped did not affect this decision. This suggests the smaller intruders might be assessing any potential costs (e.g., energetic or injury) before escalation independent of the status of their own major cheliped. After escalation, however, the success of takeover was significantly lower in intruders without a major cheliped $(N=3$ out of 14 escalations, $21.4 \%)$ than in intact intruders $(N=29$ out of 47 escalations, $61.7 \%$ ). Given that the intact intruders use their major cheliped to take a female away from their opponents during male-male contests in Pagurus species (Yasuda et al. 2014), intruders without a major cheliped undoubtedly have a lower RHP. A significant disadvantage caused by loss of the major cheliped is common in dyadic contests by decapods (e.g., Neil 1985; Smith 1992; Abello et al. 1994; Yasuda et al. 2011). P. minutus intruders without a major cheliped are, therefore, willing to initiate contests despite their lower chance of success, which seems to be an irrational choice.

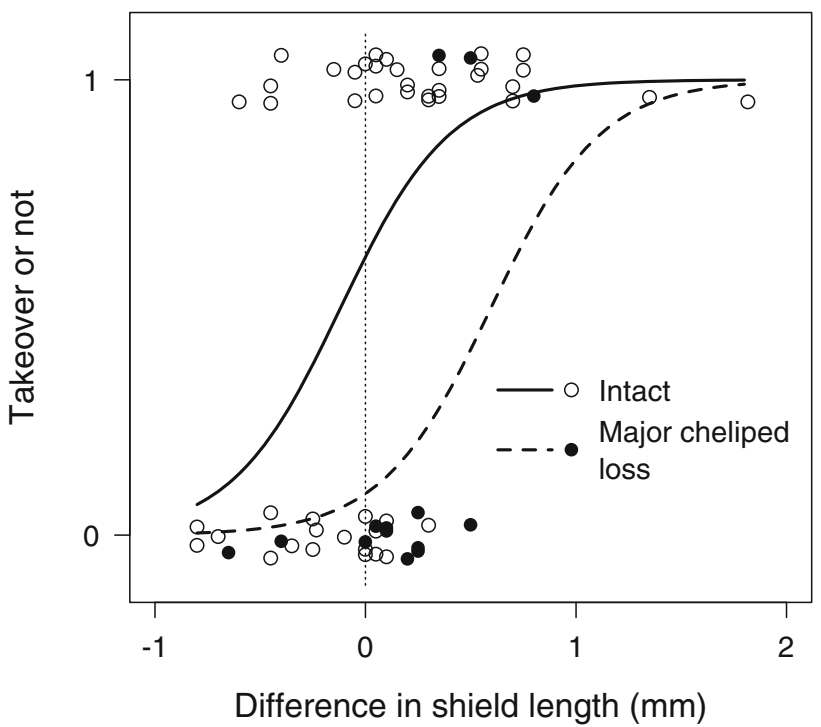

Fig. 2 Logistic regression results for whether Pagurus minutus intruders succeeded in takeover of females guarded by the owners after escalation. The curves were estimated using a GLM with a binomial error distribution. Intruders without a major cheliped had significantly decreased frequency of takeover compared with intact intruders. Values of 0 and 1 represent intruders who failed or succeeded in takeover after escalation, respectively. Shield length of the females guarded by owners was treated as the average values in the curves. The vertical dotted line indicates no body size difference between males

There are several possible explanations for this behavior. First, intruders without a major cheliped might fail to assess their actual RHP relative to that of their opponent because of the lack of assessment index in themselves. In contrast to theoretical predictions, weaker contestants often initiate aggression against stronger opponents even after visual and/or tactile assessment (Smith et al. 1994; Morris et al. 1995). This suggests that contestants cannot always assess their relative RHP, even when they are weaker than their opponent. Such mistaken assessments might also have occurred in the present study. For example, if RHP assessment depends on a given trait (i.e., an assessment index), the lack of an index might decrease the accuracy of this assessment and increase the frequency of irrational decisions. In various taxa, including decapod crustaceans, weapons are used more than body size as an assessment index for relative RHP (Barki et al. 1997; Elwood et al. 2006; Emlen 2008). Contestants of P. minutus also perform mutual RHP assessment based on major cheliped size rather than body size during all phases of male-male contests (Yasuda and Koga, in submission). Loss of the major cheliped by $P$. minutus, therefore, may cause the lack of an assessment index. If so, the intruders without a major cheliped might decrease the accuracy of mutual assessment, resulting in escalation to a fruitless contest. 
Second, despite the importance of the major cheliped, a male's RHP and its decisions based on its RHP are also strongly affected by body size. Body size differences are one of the most common factors that determine the asymmetry of RHP between males in various taxa (Andersson 1994; Hardy and Briffa 2013), and the disadvantage created by loss of the major cheliped can be overcome by a (much) larger body size than that of an intact opponent (e.g., for the shore crab Carcinus maenas; Abello et al. 1994). As is the case in other animals, the advantage of larger body size for Pagurus species during male-male contests is well known (e.g., Wada et al. 1999; Yoshino et al. 2004; Suzuki et al. 2012; Matsuo et al. 2015a). In this study, we also demonstrated that both the giving-up decision and success of takeover in intruders were affected by body size relative to their opponents in $P$. minutus. These results suggest that body size in males of $P$. minutus reflects actual RHP as well as major cheliped size (Yasuda and Koga in submission). Moreover, given that weaponless intruders tended to be larger in body size, some of them might have a relatively high RHP even without their major cheliped. All three intruders that lacked their major cheliped but that nonetheless succeeded in takeover were larger in body size than their opponents, which provides support for this possibility. Together, some uncertainty about the relative RHP between contestants reflected by body size would have remained even after intruders had lost their major cheliped.

Third, the relationship between the cost and benefit of male-male contests would affect the intruder's decision. Theoretical studies have predicted that weaker individuals are likely to initiate contests that have a low cost and high benefit (Grafen 1987; Morrell et al. 2005). Unlike other animals (e.g., Cox 1981; Leimar et al. 1991; Moore 2007), few Pagurus males are injured during male-male contests, even if physical struggles occur as a result of escalation (Yasuda et al. 2011, 2012). Thus, the cost of a contest for mates is likely to be relatively low in these species. Moreover, many studies have reported precopulatory mate guarding and intense male-male fights for guarded females in this group (Imafuku 1986; Goshima et al. 1998; Wada et al. 1999; Yasuda et al. 2011, 2014; Yasuda and Koga, in submission). Intruders try to take over a female guarded by an opponent, independent of the female's quality, in $P$. filholi (Tanikawa et al. 2012), P. middendorffii (Yasuda et al. 2012), and P. minutus (present study). This evidence suggests a scarcity and therefore high value of mature females in these species. Thus, male-male contests in Pagurus hermit crabs might therefore meet the assumptions of theoretical benefit-cost predictions; that is, intruders without a major cheliped would show no difference from intact intruders in the frequency of escalation because of the high benefit to cost ratio.
Several studies have recently explored why potentially weaker individuals might initiate aggression against stronger competitors despite a low chance of success (Just and Morris 2003; Morrell et al. 2005). Although P. minutus intruders without a major cheliped were more likely to lose a contest than intact intruders, they escalated contests rather than giving up at an early stage. This suggests that male-male contests in Pagurus hermit crabs may relate to a mistaken RHP assessment, a decision based on body size, and the favorable relationship between the benefits and costs of contests. However, further investigation will be needed to evaluate the relative importance of these explanations.

Acknowledgments We are grateful to the referees for their extensive and supportive comments and contributions. This study was financially supported by JSPS Research Fellowship for Young Scientists (No. 15J07721) to CY.

\section{Compliance with ethical standards}

Conflict of interest The authors declare that they have no competing interests.

Ethical approval All applicable international, national, and/or institutional guidelines for the care and use of animals were followed. This article does not contain any studies with human participants performed by any of the authors.

\section{References}

Abello P, Warman CG, Reid DG, Naylor E (1994) Chela loss in the shore crab Carcinus maenas (Crustacea: Brachyura) and its effect on mating success. Mar Biol 121:247-252

Andersson M (1994) Sexual selection. Princeton University Press, Princeton

Arnott G, Elwood RW (2009) Assessment of fighting ability in animal contests. Anim Behav 77:991-1004

Barki A, Harpaz S, Karplus I (1997) Contradictory asymmetries in body and weapon size, and assessment in fighting male prawns, Macrobrachium rosenbergii. Aggress Behav 23:81-91

Booksmythe I, Milner RNC, Jennions MD, Backwell PRY (2010) How do weaponless male fiddler crabs avoid aggression? Behav Ecol Sociobiol 64:485-491

Briffa M (2013) Contests in crustaceans: assessments, decisions and their underlying mechanisms. In: Hardy ICW, Briffa M (eds) Animal contests. Cambridge University Press, New York, pp 86-112

Cox CR (1981) Agonistic encounters among male elephant seals: frequency, context, and the role of female preference. Am Zool 21:197-209

Crane J (1975) Fiddler crabs of the world. Princeton University Press, Princeton

Daleo P, Luppi T, Casariego AM, Escapa M, Ribeiro P, Silva P, Iribarne O (2009) The effect of size and cheliped autotomy on sexual competition between males of the mud crab Cyrtograpsus angulatus Dana. Mar Biol 156:269-275

Elwood RW, Neil SJ (1992) Assessments and decisions: a study of information gathering by hermit crabs. Chapman and Hall, London

Elwood RW, Pothanikat RME, Briffa M (2006) Honest and dishonest displays, motivational state and subsequent decisions in hermit crab shell fights. Anim Behav 72:853-859 
Emlen DJ (2008) The evolution of animal weapons. Annu Rev Ecol Evol Syst 39:387-413

Fleming PA, Muller D, Bateman PW (2007) Leave it all behind: a taxonomic perspective of autotomy in invertebrates. Biol Rev $82: 481-510$

Goshima S, Kawashima T, Wada S (1998) Mate choice by males of the hermit crab Pagurus filholi: do males assess ripeness and/or fecundity of females? Ecol Res 13:151-161

Grafen A (1987) The logic of divisively asymmetric contests: respect for ownership and the desperado effect. Anim Behav 35:462-467

Hardy ICW, Briffa M (2013) Animal contests. Cambridge University Press, New York

Hughes M (1996) Size assessment via a visual signal in snapping shrimp. Behav Ecol Sociobiol 38:51-57

Huntingford FA, Turner AK (1987) Animal conflict. Chapman and Hall, New York

Imafuku M (1986) Sexual discrimination in the hermit crab Pagurus geminus. J Ethol 4:39-47

Juanes F, Smith LD (1995) The ecological consequences of limb damage and loss in decapod crustaceans: a review and prospectus. J Exp Mar Biol Ecol 193:197-223

Just W, Morris MR (2003) The Napoleon complex: why smaller males pick fights. Evol Ecol 17:509-522

Leimar O, Austad S, Enquist M (1991) A test of the sequential assessment game: fighting in the bowl and doily spider Frontinella pyramitela. Evolution 45:862-874

Li CY, Yang Y, Lee PY, Hsu Y (2014) Opponent familiarity and contest experience jointly influence contest decisions in Kryptolebias marmoratus. Front Zool 11:92

Maginnis TL (2006) The costs of autotomy and regeneration in animals: a review and framework for future research. Behav Ecol 17:857-872

Matsuo K, Tanikawa D, Yasuda CI, Wada S (2015a) Sex-related differences in size, function and regeneration of the major cheliped in the hermit crab Pagurus filholi. Mar Ecol 36:1391-1399

Matsuo K, Yasuda CI, Wada S (2015b) Autotomy of the major cheliped as the anti-predatory behavior in the hermit crab Pagurus middendorffii. Cancer 24:21-23

Moore PA (2007) Agonistic behavior in freshwater crayfish: the influence of intrinsic and extrinsic factors on aggressive encounters and dominance. In: Duffy JE, Thiel M (eds) Evolutionary ecology of social and sexual systems: crustaceans as model organisms. Oxford University Press, Oxford

Morrell LJ, Lindström J, Ruxton GD (2005) Why are small males aggressive? Proc R Soc B 272:1235-1241

Morris MR, Gass L, Ryan MJ (1995) Assessment and individual recognition of opponents in the pygmy swordtails Xiphophorus nigrensis and X. multilineatus. Behav Ecol Sociobiol 37:303-310

Neat FC, Taylor AC, Huntingford FA (1998) Proximate costs of fighting in male cichlid fish: the role of injuries and energy metabolism. Anim Behav 55:875-882
Neil SJ (1985) Size assessment and cues: studies of hermit crab contests. Behaviour 92:22-37

Okada K, Miyatake T (2010) Effect of losing on male fights of broadhorned flour beetle, Gnatocerus cornutus. Behav Ecol Sociobiol 64:361-369

Parker GA (1974) Assessment strategy and the evolution of fighting behaviour. J Theor Biol 47:223-243

R Core Team (2015) R: a language and environment for statistical computing. R Foundation for Statistical Computing, Vienna

Searcy WA, Nowicki S (2005) The evolution of animal communication: reliability and deception in signaling systems. Princeton University Press, Princeton

Smith LD (1992) The impact of limb autotomy on mate competition in blue crabs Callinectes sapidus Rathbun. Oecologia 89:494-501

Smith IP, Huntingford FA, Atkinson RJA, Taylor AC (1994) Strategic decisions during agonistic behaviour in the velvet swimming crab, Necora puber (L.). Anim Behav 47:885-894

Sneddon LU, Huntingford FA, Taylor AC (1997) Weapon size versus body size as a predictor of winning in fights between shore crabs, Carcinus maenas (L.). Behav Ecol Sociobiol 41:237-242

Suzuki Y, Yasuda C, Takeshita F, Wada S (2012) Male mate choice and male-male competition in the hermit crab Pagurus nigrofascia: importance of female quality. Mar Biol 159:1991-1996

Tanikawa D, Yasuda C, Suzuki Y, Wada S (2012) Effects of male size and mate quality on male-male contest in the hermit crab Pagurus filholi. Jap J Benthol 67:15-19

Wada S, Tanaka K, Goshima S (1999) Precopulatory mate guarding in the hermit crab Pagurus middendorffii (Brandt) (Decapoda: Paguridae): effects of population parameters on male guarding duration. J Exp Mar Biol Ecol 239:289-298

Yasuda C, Suzuki Y, Wada S (2011) Function of the major cheliped in male-male competition in the hermit crab Pagurus nigrofascia. Mar Biol 158:2327-2334

Yasuda C, Takeshita F, Wada S (2012) Assessment strategy in malemale contests of the hermit crab Pagurus middendorffii. Anim Behav 84:385-390

Yasuda CI, Matsuo K, Wada S (2014) Rapid regeneration of the major cheliped in relation to its function in male-male contests in the hermit crab Pagurus middendorffii. Plankton Benthos Res 9:122-131

Yasuda CI, Matsuo K, Wada S (2015) Previous mating experience increases fighting success during male-male contests in the hermit crab Pagurus nigrofascia. Behav Ecol Sociobiol 69:1287-1292

Yoshino K, Ozawa M, Goshima S (2004) Effects of shell size fit on the efficacy of mate guarding behaviour in male hermit crabs. J Mar Biol Assoc UK 84:1203-1208

Yoshino K, Koga T, Oki S (2011) Chelipeds are the real weapon: cheliped size is a more effective determinant than body size in male-male competition for mates in a hermit crab. Behav Ecol Sociobiol 65:1825-1832 